Studies in Applied Philosophy,

Epistemology and Rational Ethics

SAPERE

Annalisa Baicchi · Rémi Digonnet Jodi L. Sandford Editors

Sensory

Perceptions

in Language,

Embodiment and

Epistemology 


\section{Studies in Applied Philosophy, Epistemology and Rational Ethics}

\section{Volume 42}

\section{Series editor}

Lorenzo Magnani, Department of Humanities, Philosophy Section, University of Pavia, Pavia, Italy

e-mail: lmagnani@unipv.it

\section{Editorial Board}

Atocha Aliseda

Universidad Nacional Autónoma de México (UNAM), Mexico

Giuseppe Longo

Centre Cavaillès, CNRS-Ecole Normale Supérieure, Paris, France

Chris Sinha

School of Foreign Languages, Hunan University, Changsha, P.R. China

Paul Thagard

University of Waterloo, Waterloo, ON, Canada

John Woods

University of British Columbia, Canada 
Studies in Applied Philosophy, Epistemology and Rational Ethics (SAPERE) publishes new developments and advances in all the fields of philosophy, epistemology, and ethics, bringing them together with a cluster of scientific disciplines and technological outcomes: from computer science to life sciences, from economics, law, and education to engineering, logic, and mathematics, from medicine to physics, human sciences, and politics. It aims at covering all the challenging philosophical and ethical themes of contemporary society, making them appropriately applicable to contemporary theoretical, methodological, and practical problems, impasses, controversies, and conflicts. The series includes monographs, lecture notes, selected contributions from specialized conferences and workshops as well as selected Ph.D. theses.

\section{Advisory Board}
A. Abe, Chiba, Japan
A. Pereira, São Paulo, Brazil
H. Andersen, Copenhagen, Denmark
L. M. Pereira, Caparica, Portugal
O. Bueno, Coral Gables, USA
A.-V. Pietarinen, Helsinki, Finland
S. Chandrasekharan, Mumbai, India
D. Portides, Nicosia, Cyprus
M. Dascal, Tel Aviv, Israel
D. Provijn, Ghent, Belgium
G. D. Crnkovic, Göteborg, Sweden
J. Queiroz, Juiz de Fora, Brazil
M. Ghins, Lovain-la-Neuve, Belgium
A. Raftopoulos, Nicosia, Cyprus
M. Guarini, Windsor, Canada
R. Gudwin, Campinas, Brazil
C. Sakama, Wakayama, Japan
C. Schmidt, Le Mans, France
A. Heeffer, Ghent, Belgium
G. Schurz, Dusseldorf, Germany
M. Hildebrandt, Rotterdam,
N. Schwartz, Buenos Aires, Argentina The Netherlands
C. Shelley, Waterloo, Canada
K. E. Himma, Seattle, USA
F. Stjernfelt, Aarhus, Denmark
M. Hoffmann, Atlanta, USA
M. Suarez, Madrid, Spain
P. Li, Guangzhou, P.R. China
J. van den Hoven, Delft,
G. Minnameier, Frankfurt, Germany
The Netherlands
M. Morrison, Toronto, Canada
Y. Ohsawa, Tokyo, Japan
P.-P. Verbeek, Enschede, The Netherlands
S. Paavola, Helsinki, Finland
W. Park, Daejeon, South Korea
R. Viale, Milan, Italy
M. Vorms, Paris, France

More information about this series at http://www.springer.com/series/10087 
Annalisa Baicchi - Rémi Digonnet Jodi L. Sandford

Editors

\section{Sensory Perceptions \\ in Language, Embodiment and Epistemology}

然 Springer 


\section{Editors}

Annalisa Baicchi

Sezione di Linguistica Teorica e Applicata, Dipartimento di Studi Umanistici

University of Pavia

Pavia

Italy

\section{Rémi Digonnet}

Faculté Arts, Lettres, Langues

Université Jean Monnet Saint-Étienne

Saint-Étienne

France
Jodi L. Sandford

Dipartimento di Lettere - Lingue, Letterature e Civiltà Antiche e Moderne

University of Perugia

Perugia

Italy

ISSN 2192-6255 ISSN 2192-6263 (electronic)

Studies in Applied Philosophy, Epistemology and Rational Ethics

ISBN 978-3-319-91276-9

ISBN 978-3-319-91277-6 (eBook)

https://doi.org/10.1007/978-3-319-91277-6

Library of Congress Control Number: 2018940628

(C) Springer Nature Switzerland AG 2018

This work is subject to copyright. All rights are reserved by the Publisher, whether the whole or part of the material is concerned, specifically the rights of translation, reprinting, reuse of illustrations, recitation, broadcasting, reproduction on microfilms or in any other physical way, and transmission or information storage and retrieval, electronic adaptation, computer software, or by similar or dissimilar methodology now known or hereafter developed.

The use of general descriptive names, registered names, trademarks, service marks, etc. in this publication does not imply, even in the absence of a specific statement, that such names are exempt from the relevant protective laws and regulations and therefore free for general use.

The publisher, the authors and the editors are safe to assume that the advice and information in this book are believed to be true and accurate at the date of publication. Neither the publisher nor the authors or the editors give a warranty, express or implied, with respect to the material contained herein or for any errors or omissions that may have been made. The publisher remains neutral with regard to jurisdictional claims in published maps and institutional affiliations.

Printed on acid-free paper

This Springer imprint is published by the registered company Springer Nature Switzerland AG

The registered company address is: Gewerbestrasse 11, 6330 Cham, Switzerland 


\section{Contents}

\section{Introduction}

The Language of Senses: A Window onto the World. . . . . . . . . . ix Annalisa Baicchi, Rémi Digonnet, Jodi L. Sandford

\section{Part I Theoretical Perspective}

1 Our Biological Mind in the Modern Verbal World . . . . . . . . . . 3 Gordon H. Orians

2 Embodied Semantics and the Mirror Neurons: Past Research

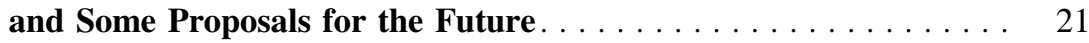
Paolo Della Putta

3 What is not Said: Metaphor and the Deflationary Account . . . . 45 Chris Genovesi

4 Do Metaphors Mean or Point? Davidson's Hypothesis Revisited . . . . . . . . . . . . . . . . . . . . . . . 59 Weiguo Qu

\section{Part II Applied Perspective}

5 A Neuroimaging Investigation into Figurative Language and Aesthetic Perception . . . . . . . . . . . . . . . . . . 77 Francesca Citron and Emmanouil A. Zervos

6 Ception and the Discrepancy Between Vision and Language . . . . 95 Annalisa Baicchi

7 Methodological Approaches and Semantic Construal of the SeEIng Domain in English . . . . . . . . . . . . . . . . 111 Jodi L. Sandford 
8 Metaphors for Musical Motion-Beyond Time Is Motion . . . . . . . 133 Nina Julich

9 Defining Taste in English Informant Categorization . . . . . . . . . . 155 Marco Bagli

10 The Linguistic Expression of Smells: From Lack

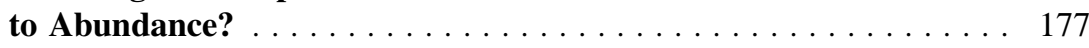
Rémi Digonnet

11 Synaesthesia and Other Figures. What the Senses Tell Us About Figurative Language . . . . . . . . . . . . . . . . . . . . . 193 Francesca Strik Lievers

Contributors . . . . . . . . . . . . . . . . . . . . . . . 209

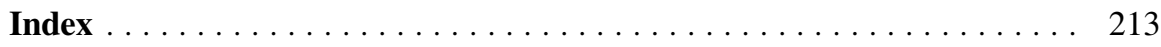




\title{
Chapter 2 \\ Embodied Semantics and the Mirror \\ Neurons: Past Research and Some \\ Proposals for the Future
}

\author{
Paolo Della Putta
}

\begin{abstract}
Embodied approaches to language propose that higher order mental processes, such as meaning construction, rely on the sensorimotor neural devices of our brain (Barsalou in Behav Brain Sci 22:577-660, 1999; Tettamanti et al. in J Cog Neurosci 17:273-281, 2005; Pulvermüller in Symbols and embodiment: debates on meaning and cognition. Oxford University Press, Oxford, pp. 85-116, 2008). According to the Embodied Semantics paradigm, linguistic concepts are represented in the brain within partially overlapping neural substrates recruited to enact and experience the action a word refers to (Kemmerer in Lang Cogn 7(3):450-475, 2015). Mirror neurons are a class of cells capable of discharging congruently both when a person executes an action and when s/he perceives the same action performed by another individual. Recent research has demonstrated the involvement of mirror neurons in motor language processing: perceiving a word such as "to grasp" activates the same brain motor areas triggered as if we were enacting the same action (Buccino et al. in Cogn Brain Res 24:355-363, 2005; Kemmerer \& Castillo in Brain and Language 112:54-76, 2010). The debate is open on whether similar somatotopic mirror neuron activations happen also in experiments involving abstract motor language comprehension, with scholars debating this point and trying to ascertain if congruent motor areas are triggered both when the motor component of a sentence is concrete (e.g. "to kick the ball"), and when it is abstract (e.g. "to kick the bucket", Aziz-Zadeh and Damasio in J Physiol 102:35-39, 2008; Cacciari et al. in Brain Lang 119:149-157, 2011). In this chapter I offer a critical overview of mirror neurons involvement in concrete and abstract motion meaning construction and discuss some of the issues raised against the hypothesis that language comprehension makes use of the mirror neuron system. I also stress the importance that further research be conducted which takes into due account linguistic relativity and second language competence.
\end{abstract}

\footnotetext{
P. Della Putta $(\bowtie)$

University of Modena and Reggio Emilia, Modena and Reggio Emilia, Italy

e-mail: paolo.dellaputta@unimore.it
} 


\section{Introduction}

The so-called first-generation cognitive science looks back to the Cartesian distinction between res cogitans and res extensa (Descartes 1637; see Chomsky 1966, for a Cartesian approach to language), namely our mind, deputed to thinking and reasoning, and our body, whose task is to interact with the "outside" world. This view implies that the activity of the mind is body-independent and divided into "low" processes, such as perception and motor control, and "high" processes, such as thought and language. In Descartes' view, knowledge deriving from sense perception is fallible, whereas its "true" and flawless counterpart are innate concepts stored in our mind. Yet, according to this account of cognition, human senses do provide a kind of knowledge that, although fallible, contributes to creating dependable knowledge. The French philosopher's challenge was then to explain how flawless and reliable knowledge could be created also on the basis of fallible sense experience, a challenge that was resolved by resorting to an early version of representationalism, according to which the content of sense perception must be distinguished from the cognitive processes it undergoes. Only these processes (i.e. mental elaboration and representations of sensory experience) can be considered reliable because of their mathematical nature. Therefore, Descartes maintained that there is a distinction between perception and its mental representation, recognizing the mental representation as the only real, dependable knowledge (Atkinson 2012). Concepts are, according to this view, abstract entities holding only a functional relationship with the body: The input our body gives to our mind has to be translated into an arbitrary and symbolic "language of thought", that is, the bridge between perception and reasoning (Fodor 1975).

During the last three decades a new and solid alternative to this main paradigm has developed quickly, calling for a more naturalistic theory of mind and language. This new view, defined as "embodied cognition" or simply "embodiment", refuses the Cartesian mind-body dualism and states that the activity of our mind is grounded in our bodily experience. Adopting a phenomenological approach, the embodied perspective on cognition refuses the long standing, traditional view of rationalism (the existence of a mind-independent reality and the existence of absolute truths) and proposes a new conception of our "inner" activity based on the following statements (Johnson and Lakoff 2002 and Dove 2016 for a review):

1. our minds, the very kind of minds that we possess, are necessarily embodied in our living organism;

2. our conscious minds are embodied, not in the brain alone, but in our organism considered as the complex system of organs and processes of our living bodies;

3. our consciousness is necessarily shaped by the way our bodies are.

Lakoff and Johnson (1999) called this new conception of the mind the "embodied mind" paradigm, in sharp contrast to the Fodorian and Chomskyan "disembodied mind" paradigm.

Embodied approaches to cognition have been seriously criticized throughout the years and have often been accused of an excessive empiricism, i.e., giving unneces- 
sary importance to the role played by the external input in experience and meaning construction, ignoring the fact that the human being is endowed with innate capacities and that the initial state of our mind is not a "tabula rasa" (see Rakova 2002 for a summary of these issues).

The reply to these criticisms is well documented in the literature (see Johnson and Lakoff 2002 for a review) and bases its argumentation on two facts:

1. experience is an interactive process, involving both neural and psychological activity from the organism and the characteristics of the environment in which the organism is situated;

2. consciousness and meaning rise not only from the subject, i.e. the internal structure of the organism and from the object, the external input, but from their relationship elaborated by the organism itself, this being considered as a mind-body unity placed in relation with the "outside" world.

Embodied approaches to cognition do not claim that the representation of concepts does not exist at all, but propose instead that their existence is strongly dependent on our bodily experiences and not solely dependent upon an inner mental entity.

The embodied approaches to cognition have strongly informed linguistic and semantic theories, thus giving birth to a large body of experimental research aimed at better understanding the relationship between linguistic concepts and bodily sensory-motor processes. Broadly speaking and with the simple aim of giving here a brief up-to-date revision of the Embodied Semantic paradigm, four main theoretical approaches are to be accounted for today. The first, probably no longer consistent with the experimental evidence collected in the last 20 years of investigations (Meteyard et al. 2012), is the unembodied theory, according to which linguistic concepts have no relationship to the sensory-motor system as they are fully amodal independent structures.

The secondary embodiment theory states that the neural architecture of concepts is mainly amodal, i.e., it relies on specific cortical areas that serve as semantic hubs. Secondary embodiment theories postulate that the amodal semantic hubs have a temporal and experience-based relationship with the sensory-motor system, i.e., amodal concepts, once activated, are able to trigger a secondary and temporarily posterior activation of the sensory-motor areas which these amodal concepts entail (Caramazza and Mahon 2003). The sensory-motor areas are, according to this view, passively and secondarily activated by a concept and not vice versa, as other theories about embodiment postulate (see also Lambon Ralph 2014 for the so-called "Hub-andSpoke model", an update of the theoretical framework involving semantic hubs).

According to the weak embodiment theory, purely semantic areas, i.e. the abovementioned "semantic hubs", are distributed in the brain cortex as a network that has strong ties with the cortical sensory-motor areas. Purely conceptual areas have a partial-dependent relationship with sensory-motor areas, which are somatotopically and congruently activated by meaning construction processes. The weak embodiment perspective on meaning construction does not reject the idea that a purely conceptual activity exists but, contrary to what is postulated by the unembodied and secondary 
embodiment stances, this conceptual activity is strongly linked to the activation of the sensory-motor system, viewing this activation as a parallel and unavoidable process in semantic comprehension and production (Barsalou 1999; Meteyard et al. 2012).

According to the fourth theoretical account of embodiment-the so-called strong embodiment theory, semantic processing is completely dependent on the sensorymotor system, in that semantic information is totally retrieved and constructed by the direct modulation of primary cortical areas such as motor and premotor cortex "as if" we were actively performing the very same action that is perceived or produced in an utterance. To put it with Aziz-Zadeh and Damasio (2008: 35): "linguistic concepts" (propositions) "are represented within the same sensory-motor" (neuronal) "circuitry in which the enactment of the same concept relies".

The debate on the degree of involvement of the sensory-motor system in meaning construction has reached an impasse, with scholars from different theoretical backgrounds facing many difficulties in giving a unanimous interpretation of the empirical findings (see e.g., Mahon 2015 for a defense of the amodal semantic representation, and Dove 2015 for a review of the issues involved in this debate). Zwaan (2014) proposes a way out from this theoretical conundrum maintaining that more attention should be paid to the degree of embeddedness of the utterance in the environment where it is uttered. ${ }^{1}$ According to Zwaan, one of the major problems in the literature debating the recruitment of sensory-motor areas in meaning construction is that scholars have so far focused almost solely on single words or sentences, staying away from the discussion of the role of the communicative context. Zwaan invites scholars to reconsider the role of context in the interpretation of the different findings about sensory-motor activation during meaning construction. The overlap between the communicative situation and the referential situation (i.e. what the discourse is about) is, in Zwaan's view, the variable capable of modulating the activation of the sensory-motor system during language comprehension. Communicative acts such as demonstrations or instructions are strongly embedded in the environment and would require stronger activation of sensory-motor areas to be comprehended. Conversely, abstractions do not refer to any environment in particular, but concern different kinds of abstract concepts such as theories, thoughts, etc. According to Zwaan, understanding a text of this sort (such as a legal document or a scientific article) would not require any sensory-motor activation, but would strongly resort to abstract symbols. Nevertheless, the utterer might want to enhance the comprehensibility of an abstract text by using conceptual metaphors or metonymies, and the comprehension thereof might require the enactment of the sensory-motor areas even if these figures are embedded in an abstract context. Empirical findings corroborating Zwaan's ideas have been reported in Cuccio et al. (2014), where it is demonstrated that motor activation during the comprehension of action related words is modulated by the context of the utterance. Both the weak and the strong embodiment approaches on meaning construction entail in their theoretical constructs the notion of simulation, being it either the solely and primary feature of semantic activity or a parallel

\footnotetext{
${ }^{1}$ For the sake of simplicity, we use the terms "utterance" and "utter" for both the oral and written use of language.
} 
process to purely conceptual activity. As Meteyard et al. (2012: 793) stress in their review article on embodiment, "comprehension involves the simulation of whatever the language describes, and this simulation necessarily recruits sensory and motor representations". Linking action to language, i.e., more broadly speaking, "embodying" language, presupposes a neural substrate capable of endowing our brain with simulative skills that can enact embodiment. Cerebral Mirror Areas are regions of the human brain that trigger congruently both when an action is performed and when the very same action is observed or, in some cases (see below for details), when its linguistic representation is perceived. Cerebral regions with these features are the posterior part of Broca's area, the premotor cortex, the inferior parietal lobule and the anterior intraparietal sulcus (Kemmerer 2015). Cerebral mirror areas are thought to be the neural substrate on which semantic simulation finds its "body" and on which embodied theories of language are constructed (Adenzato and Garbarini 2006; Glenberg and Gallese 2012; Fogassi et al. 2013).

Crucially, cerebral mirror areas are endowed with Mirror Neurons (MNs), a class of cells capable of discharging congruently both when a person executes an action and when $\mathrm{s} /$ he perceives the same action made by another individual. MNs are considered to be the cell-level mechanism that provides mirror areas with simulating properties (Cook et al. 2014; Kemmerer 2015, but see Hickok 2014 for counter opinions). Thus, MNs are thought to be a part of the neurophysiological mechanism that enacts Embodied Semantics, even though caution is in order when dealing with this topic because there is still ongoing debate in the scientific community about the existence of MNs in the human brain and, consequently, their involvement in Embodied Semantics (Hickok 2014; Caramazza et al. 2014; see Sect. 5). In recent years, in-depth discussion on this topic has commenced, focusing in particular on motion verbs: According to a number of studies (see, e.g. the thematic issue 112 of Brain and Language 2010) there is evidence for an association between the activation of cerebral mirror areas and action word/concept processing.

In this chapter I deal with these queries: Is the activation of mirror areas through MNs a clear fact or do we need further investigation in this field? And, secondly, is the activation of mirror areas the same in all linguistic contexts? What happens if we consider the same motion word, say "to kick", in metaphorical and non-metaphorical contexts?

This chapter is organized as follows: Sect. 2 attempts to better define the concept of body and its relevance for the Embodied Semantic paradigm. Section 3 is entirely dedicated to the properties of the MN system and Sect. 4 offers a review of some very recent literature investigating the relationship between motion verbs, the activation of the brain sensory-motor system, and MNs. Section 5 deals with the scientific debate about this topic, giving voice to more skeptical studies about the involvement of MNs in meaning construction. Section 6 argues that two important issues have hitherto received less attention in the experiments: Linguistic relativity and the study of embodied semantics in second language speakers. 


\title{
2 The Concept of "Body"
}

When one talks about embodiment, one immediately thinks about the body. But, if we distance ourselves from a sort of folk psychology definition of the body, we realize that the concept is not a simple one and, needless to say, it is a core matter when talking about Embodied Cognition. As Violi (2003) states, the concept of body is defined and built by the different disciplines that investigate it: The body of medicine is not the same as the body of psychology, neither is it the same as the body of neurosciences and so on. Different scholars have proposed their own idea and conception of body and the debate about it is still ongoing. The equation body-brain proposed by Lakoff and Johnson (1999) has been extensively criticized, especially by Violi (2003, 2008) and Zlatev (2007).

According to Zlatev (2007), reducing the body to the neural circuitry of our brain would be a reductive approach to cognition as it lacks the important notions of context and physical environment; according to Violi "the body is a constructed concept and, as such, cannot be reduced to purely neuro-physiological aspects nor to the brain. The kind of body that needs to be incorporated into Cognitive Semiotics is a phenomenological one" (Violi 2003: 202; see also Dirven 2005; Dirven and Ruiz de Mendoza 2010; and Sambre 2012 for a broader discussion). ${ }^{2}$ Violi aptly defines the concept of "phenomenological body", a crucial definition for the perspective adopted in this chapter:

\begin{abstract}
Through perception the subject meets the world in the first place and begins to give meaning to it. Phenomenological and perceptive meaning is transformed into linguistic meaning through the corps propre ${ }^{3}$ which founds, at one and the same time, the subjectivity of consciousness and the exteriority of the world. [...] In Merleau-Ponty's phenomenology, too, external and internal world are not separate and in opposition with one another, but related to each other via the mediation of the corps propre that operates, in a way, as translator of perceptually constructed meaning into linguistic and conceptual meaning. (2008: 57)
\end{abstract}

Following the phenomenological perspective proposed by Violi, going back to Merleau-Ponty's work on phenomenology of perception, the body is "that strange object which uses its own parts as a general system of symbols for the world, and through which we can consequently 'be at home' in that world, 'understand' it and find significance in it" (Merleau-Ponty 1962: 237). Merleau-Ponty's view stresses the fact that we cannot reduce the idea of the body to its neural representation in our brain. We should rather consider it as a living, perceptive entity in which the relationship between brain and effectors (like arms, legs, mouth, etc.) play an important role in understanding and finding significance in the world around us, to support Merleau-Ponty's words. According to Gallese (2005), following the philosophical perspective of the French phenomenologist, the definition of body that better suits

\footnotetext{
${ }^{2}$ Violi speaks in her article about "Cognitive Semiotics" and not about "Embodied Semantics". Cognitive Semiotics is an interdisciplinary science that makes use of methods and findings of both Humanities and Cognitive Science. Of course the core topic is the study of meaning construction and, for our purposes, we can consider it very close to Embodied Semantics.

3"Living body" is the English translation for the French "corps propre".
} 
Embodied Cognition is what he calls "brain-body system", i.e., the concrete living entity and its neural representation.

Thus, cognition is no longer merely a matter of "high" processes. The very first step taken by the human being toward cognition is a bodily one in which the first, preconscious and non-inferential cognitive activity happens in those regions of our brain that have classically been considered "low" processes areas, like the motor cortex and posterior parietal areas. Areas of the brain cortex that were classically considered non-cognitive, but merely in charge of bodily processes have been demonstrated to be involved in cognitive processes such as reasoning, imagination, thought, and meaning construction (Gallese 2008; Rizzolatti and Sinigaglia 2008). The simulating properties of MNs are thought to be the neural mechanism that endorses the brain with such cognitive faculties.

\section{The Mirror Neuron System and Neural Simulation}

During the last three decades, numerous studies have provided evidence that the macaque brain cortex contains MNs, cells that are triggered congruently by both the perception and the production of certain actions. ${ }^{4}$ Groups of MNs have been discovered in different regions of the primate brain cortex, particularly in the ventral and dorsal premotor cortex and in some areas of the primary motor cortex (Gallese et al. 1996; Rizzolatti et al. 1996; Ferrari et al. 2003; Raos et al. 2007). According to these studies, the activation of MNs is somatotopically organized, showing that MNs are effector-specific (their activation is strongly related to the use of certain parts of the body) and manner/goal-sensitive, stressing the peculiar fact that they activate differently according to the aims and manners in which a specific action is performed, as in grasping/holding (aims) and precision grip or strong grip (manners). According to Rizzolatti and Sinigaglia (2008), MNs would represent a motor act vocabulary capable of discharging when performing certain actions with certain effectors, as well as when perceiving those very same actions. In a nutshell, MNs put in action an automatic, partially somatotopically-organized and unconscious process by which the perception of actions evokes an internal, neuronal simulation of these actions as if the individual were performing them with his/her own body (Rizzolatti et al. 2001; Rizzolatti and Craighero 2004; Rizzolatti and Sinigaglia 2008).

The idea that the monkey's brain acts in the precise moment of perception provoked the question as to whether the human brain also had the same property and, consequently, a number of studies have been carried out on humans to give evidence of the presence of MNs. To the best of our knowledge, only one study has reported the direct evidence that also the human brain is endowed with single cells capable of dis-

\footnotetext{
${ }^{4}$ The literature about MNs counts more than 800 published papers (Kilner and Lemon 2013) and an attempt to review it here would be impossible. We limit ourselves to summarize the issues related to the topic this chapter deals with. We address the reader to Kilner and Lemon's paper and to Cook et al.'s paper (2014) for a complete picture of what MNs are and what they are for in the human brain.
} 
charging consistently both when an action is acted and when it is observed (Mukamel et al. 2010), but, nevertheless, there is a growing body of evidence, although indirect, that also humans, not only primates, are equipped with MNs or, at least, with cells with "mirror properties" (Cook et al. 2014).

In effect, various experiments, performed with different techniques such as fMRI, TMS and MEG, have substantially demonstrated the existence, also in the human brain, of such a resonance mechanism and these discoveries suggest the presence of MNs in the human cortex, in particular in frontal and parietal lobes (see Gallese 2008, and Fadiga et al. 2005 for a broader review of these studies). Particularly relevant for linking language and action is the fact that the presence of MNs has been discovered in the cortex area BA 44, i.e. Broca's area, classically considered to be involved both in language production and in hand movement planning and control (Fadiga and Craighero 2004).

Human MNs show peculiar characteristics that monkeys do not possess:

1. seeing other humans doing something triggers MNs activity in the premotor cortex in a somatotopic fashion;

2. seeing non-humans doing something triggers MNs activity only if that action is part of the observer's motor repertoire (seeing a dog barking does not trigger any reaction in humans, see Buccino et al. 2004);

3. some MN clusters positioned in the premotor cortex are endowed with reverse capacities, i.e., a complete discharge suppression during action observation. According to Kraskov et al. (2009) and to Mukamel et al. (2010), this discharge suppression is the mechanism that inhibits concrete physical activation during action observation.

4. perceiving motor action via language, and not vision, triggers $\mathrm{MN}$ activity in a partially somatotopic fashion and in different contexts.

In particular, movement-related sentences are shown to be a strong input for the activation of MNs in the human brain cortex and these findings, which I deal with below, seem to support the Embodied Semantic theories, at least for movement in language. When perceiving a linguistic item related to the movement of a particular body part, our brain activates a simulation of that very action and these neural activations are considered the first step toward the semantic comprehension of movement-related sentences (Gallese and Lakoff 2005; Aziz-Zadeh and Damasio 2008; Fernandino and Iacoboni 2010).

\section{Embodied Semantics and Mirror Neurons}

While in the disembodied view a concept is thought as an abstract symbol having a purely arbitrary association with a person's sensory-motor experiences, the Embodied Semantic stance sees concepts as "perceptual symbols"- that is, patterns of neural activity in the sensorimotor cortices themselves (Barsalou 1999). As reported 
in Sect. 1, one of the core tenets of both weak and strong embodiment theories is the notion of simulation, i.e., the (re)activation of the sensory-motor system involved in the physical enactment of the action, whether uttered, seen, heard or imagined. The peculiar property of human MNs, that of being activated also by language items gave support to the Embodied Semantics paradigm: Could MNs be its neural substrate?

A model worth mentioning here is Pulvermüller's Semantic Somatotopic Model (Pulvermüller 2005, 2008). According to this model, verified by experimental studies, perceiving and producing linguistic items strictly related to different body effectors (like to lick, to kick, and to pick) activates premotor areas somatotopically. When we hear or read the verb to lick, our premotor cortex activates the same areas that would be activated if we were about to perform that action with our tongue and mouth muscles. The first studies that demonstrated that movement verbs are represented, in our premotor cortex, in the same areas used to plan and perform these movements, in accordance with Pulvermüller's Semantic Somatotopic Model, has been conducted by Hauk and colleagues (2004). This study used event-related fMRI to record the activation of areas in the premotor and motor cortex during a reading task of action words referring to face, arm, or leg actions. The mirror areas that triggered during the reading task were adjacent to, or overlapped with areas activated by the actual movement of tongue, fingers, or feet (see also de Lafuente and Romo 2004 for a commentary of Hauk et al. study).

Furthermore, Aziz-Zadeh et al. associated, in a single study, the visual perception of an action and its linguistic description, aiming to demonstrate that visual and linguistic stimuli activated overlapping areas in the premotor and motor cortex of human brain:

\footnotetext{
The main aim of the present study was to determine whether phrases describing actions made with different effectors (hand, foot, mouth) would activate those sectors of the [...] cortex (motor and premotor areas) that are active when an individual observes actions made by others with the same effectors. [...] Congruence between the cortical sectors activated by observing actions and by their verbal descriptions provides evidence for an involvement of premotor areas with Mirror Neuron properties in re-enactment of sensory-motor representations during conceptual processing of linguistic phrases describing actions. (2006: 4)
}

This study provided strong evidence about congruent resonance of premotor cortex in both linguistic and non-linguistic motor tasks and supported the somatotopic activation studied by Pulvermüller.

Tettamanti et al. (2005) and Buccino et al. (2005) carried out two very similar experiments with TMS and fMRI techniques. The participants in both experiments were asked to listen to utterances related to arm/hand actions (e.g. I grasp the knife), mouth/lips actions (e.g. I bite the apple), and leg/foot actions (e.g. I kick the ball) and, as control group, to sentences describing mental states (e.g. I sincerely appreciate). Both experiments found that listening to effector-related sentences modulates the premotor cortex activity as if the subjects were performing those actions:

The main findings of the present study was a clear modulation of the activity of the motor system during listening to sentences expressing foot/leg and arm/hand actions. [...] These data strongly support the notion that the processing of language material modulates, at least for sentences expressing a motor content, the activity of the motor system and that 
this modulation specifically concerns those sectors of the motor system where the effector involved in the processed sentence is motorically represented. (Buccino et al. 2005: 278)

Moreover, as expected, listening to mental states sentences did not trigger any premotor cortex areas.

More recently, Kemmerer et al. (2008; see also Kemmerer and Gonzalez Castillo 2010) conducted an experiment where they tested neural activation in the premotor cortex related to five different semantic fields:

1. "running" words (run, jog, walk);

2. "speaking" words (mumble, whisper, yell);

3. "hitting" words (hit, poke, jab);

4. "cutting" words (cut, slice, hack);

5. "change of state" words (shatter, crack, smash) as control group.

The results confirm the findings of the previous experiments: Hearing running, hitting and cutting words activated somatotopically areas in the premotor and motor cortex. Change of state words did not activate, as was expected, motor areas of the brain. The only incongruent finding of this experiment is related to the "speaking" words (semantic field Number 2) that did not engage motor regions related to lip/tongue areas, in contrast with some previous experiments (Hauk et al. 2004; Tettamanti et al. 2005; see Kemmerer and Gonzalez-Castillo 2010 for a discussion).

Foroni and Semin (2009) conducted a study to ascertain whether linguistic stimuli referring to emotional states (happiness and anger) could trigger muscle activation as if the subject were actually smiling (an action related to happiness) or frowning (an action related to anger). The researchers used electromyography (i.e., a medical technique that records the electrical activation of muscles) to find out if the zygomatic major and the corrugator supercilii muscle regions were triggered by the reading of sentences related to facial expressions of happiness and anger, such as to smile, to laugh, and to grin. Furthermore, the participants read also adjectives related to the two states of mind under investigation such as funny, entertaining, and irritating. The results clearly demonstrated congruent motor resonance in both cases, i.e., both while reading a sentence with an action verb related to an emotional state and while reading a word related to a description of an emotional state. However, the strength of the activation varied significantly, the intensity of electricity being stronger with action sentences than with words describing emotional states.

The more recent study of de Vega et al. (2014) went one step further and set out to verify if motor-resonance phenomena are to be found also during the comprehension of non-factual statements. The participants were asked to perform two different tasks. The first was to read factual, negative or contrafactual paragraphs containing two different meaning conditions: (i) clauses describing a person doing a manual action (such as to unwrap a present) and (ii) clauses describing a person passively observing an object. The second task was to watch short videos showing manual actions that were similar to those described in the paragraphs. An fMRI recorded congruent somatotopically activation during video observation and action-related sentence reading, with the latter showing more strength than the former, which were, 
Table 1 Sentences chosen in Glenberg's et al. (2008) experiment

\begin{tabular}{l|l|l|l}
\hline Sentence type & Toward movement & Away movement & No transfer \\
\hline Concrete & $\begin{array}{l}\text { Marco ti dà le carte. } \\
\text { [Marco gives you the } \\
\text { paper] }\end{array}$ & $\begin{array}{l}\text { Tu dai le carte a Marco. } \\
\text { [You give the papers to } \\
\text { Marco] }\end{array}$ & $\begin{array}{l}\text { Tu leggi le carte con } \\
\text { Marco. } \\
\text { [You read the papers with } \\
\text { Marco] }\end{array}$ \\
\hline Abstract & $\begin{array}{l}\text { Anna ti delega le } \\
\text { responsabilità. } \\
\text { [Anna delegates you the } \\
\text { responsibilities] }\end{array}$ & $\begin{array}{l}\text { Tu deleghi le } \\
\text { responsabilità ad Anna. } \\
\text { [You delegate the } \\
\text { responsibilities to Anna] }\end{array}$ & $\begin{array}{l}\text { Tu discuti delle } \\
\text { responsabilità con Anna. } \\
\text { [You discuss the } \\
\text { responsibilities with } \\
\text { Anna] }\end{array}$ \\
\hline $\begin{array}{l}\text { Nonsense } \\
\text { (control) }\end{array}$ & $\begin{array}{l}\text { Tu canti le carte con } \\
\text { Daniele. } \\
\text { [You sing the papers with } \\
\text { Marco] }\end{array}$ & $\begin{array}{l}\text { Daniele ti pulisce le } \\
\text { responsabilità } \\
\text { [Daniele cleans you the } \\
\text { responsibilities] }\end{array}$ & \\
\hline
\end{tabular}

nevertheless, more extended in the brain cortex. As expected, no motor resonance phenomena were recorded during the reading of non-motor sentences. Furthermore, de Vega and colleagues found that all the three sentence conditions (factual, negative and contrafactual) triggered very similar cerebral areas, as if the subjects were executing these very same actions, in spite of the different degree of reality expressed by the sentences.

The study of Aziz-Zadeh et al. (2006, partially quoted above) tested the provocative idea that also processing abstract language could modulate the motor system activity by considering widely used metaphors related to actions such as to bite the bullet and to kick the bucket. The experimenters did not find congruent activation in the premotor cortex as the ones they found when the same subjects were watching videos of mouth or foot actions and listening to concrete sentences (like to bite an apple or to kick the ball, see above). According to Aziz-Zadeh and colleagues, metaphorical sentences did not trigger the motor system because the expressions they had chosen were over-practiced in the English language. In those cases, the metaphorical meaning is more salient than the literal meaning (a movement) and this would explain the inactivity of the motor and premotor cortex (Aziz-Zadeh and Damasio 2008).

Compared with these findings and the hypotheses behind them, Glenberg and colleagues took a step backward. They decided not to test metaphorical sentences as such but to enquire into the possibility that motion verbs would trigger the motor system also if presented in an abstract fashion. For this experiment, the Italian sentences chosen are shown in Table 1 (Glenberg et al. 2008: 911), here indicated with their English glosses in square brackets.

In these sentences the Italian verb delegare (to delegate) has the same movement pattern albeit abstract as the Italian verb dare (to give), and the two verbs share the same verbal complements (something to somebody). 
Table 2 Types of sentences created for Cacciari's et al. (2010 and 2011) experiment

\begin{tabular}{l|l}
\hline Sentence type & Example \\
\hline Literal & $\begin{array}{l}\text { Il poliziotto segue il ladro } \\
\text { [The policeman follows the thief] }\end{array}$ \\
\hline Metaphorical & $\begin{array}{l}\text { La ragazza segue sempre il suo istinto } \\
\text { [The girl follows her instinct always] }\end{array}$ \\
\hline Idiomatic & $\begin{array}{l}\text { Giuseppe segue le orme di suo padre } \\
\text { [Giuseppe follows the footsteps of his father] }\end{array}$ \\
\hline Fictive & $\begin{array}{l}\text { La ferrovia segue il corso del fiume } \\
\text { [The railway follows the stream of the river] }\end{array}$ \\
\hline $\begin{array}{l}\text { Control } \\
\text { sentences }\end{array}$ & $\begin{array}{l}\text { Cristina considera l'idea molto interessante } \\
\text { [Cristina considers the idea very interesting] }\end{array}$ \\
\hline
\end{tabular}

The sentences created as control items are composed of mental activity verbs (such as to consider, to find, to think etc.) and a syntactic structure similar to that of the non-control stimuli

The experiment showed that, both in a behavioral test and in a TMS test, listening to the above mentioned sentences modulates the premotor cortex in a very similar way in both contexts. Furthermore, the no transfer sentences had a weaker influence on the motor system, this being probably further evidence of the fact that language comprehension makes use of motor schemas, schemas that have not been recognized in these sentences.

Two other experiments (Cacciari et al. 2010, 2011) returned to metaphoric language as proposed by Aziz-Zadeh et al. (2006). Given the fact that motion sentences modulate the cortex activity as if our body were performing that very action both in concrete and abstract contexts, the metaphorical context appeared worthy of further and more adequate analysis.

Cacciari and colleagues chose 27 common verbs in Italian related to leg movements such as follow, cross and run. They created four types of sentences with each verb according to Table 2, where they are indicated with their English glosses in square brackets:

The recordings of MEPs (motor events potentials) of the participants while reading these sentences clarify somehow what was shown in Aziz-Zadeh et al. experiment (2006). Cacciari and colleagues discovered that the gradient of neural activation was as follows:

$$
\text { literal }>\text { metaphorical }>\text { fictive }>\text { idiomatic }
$$

In literal and metaphorical sentences the motion verb preserves its core meaning (a movement), but the activation differs because in metaphorical meaning the arguments vary in their nature: The object in literal sentences is animated or capable of physical movement while in metaphorical sentences it is inanimate and abstract. In fictive sentences the animatedness of the subject appeared to play a crucial role. When unanimated, no neural activation was recorded; when animated, very weak 
activation was recorded. Lastly, motion verbs in idiomatic expressions (the so called 'over-practiced' metaphors in Aziz-Zadeh and Damasio 2008) have lost their action components as the relationship between meaning and words in idiomatic expressions is usually lost in the evolution of the idiom and this would be the reason why our brain is no longer able to recognize the motion component.

The study by Cacciari and Pesciarelli (2013) is a follow-up of the above reviewed studies of Cacciari et al. (2010, 2011). Cacciari and Pesciarelli's study aimed to further verify if the stimuli presentation protocol had an influence on the result validity of the two previous experiments. In particular, the authors focused on the fact that in their 2010 and 2011 studies the sentences were presented in three different segments, i.e. first the noun phrase, second the verb, and third the sentence completion that clarified the literal or figurative nature of the input item. In their 2013 study, the same sentences were presented as single units and the subjects were asked to judge the meaningfulness of the sentences within $3000 \mathrm{~ms}$; the answer had to be given by using either the hand, finger, or foot. Cacciari and Pesciarelli found incongruent results as for what the gradient neural activation concerns, i.e., they detected activation only for literal change of location and not for other non-literal movements. Methodological and theoretical issues are raised by the two authors and are discussed in detail in their paper. Suffice it here to quickly mention the two following points: (1) it has to be clarified in which way the presentation of the stimuli interferes with neural activation. Cacciari and Pesciarelli report that, according to the Linguistic Focus Hypothesis proposed by Taylor and Zwaan (2008), "motor activation may be shortlived at sentential verb. Hence, it may progressively fade away after the verb for being undetectable when the subject emits the sensibility judgement at the end of the sentence" (Cacciari and Pesciarelli 2013: 7), and this would partially explain the incongruences between the three studies by Cacciari and colleagues. (2) Cacciari and Pesciarelli's results partially undermine the claims of a necessary and causal contribution of sensory-motor activation in the semantic processing of motion verbs. Once more, and accordingly to Zwaan's contextual hypothesis (see Sect. 1), the context in which the sentences are embedded seems to modulate the activation of cerebral mirror areas, as is confirmed by the detectability of motor resonance in literal change of location sentences solely.

The results of Cacciari and colleagues contrast with those of other scholars that set out to verify the engagement of the motor system in non-literal language comprehension. Boulenger et al. $(2009,2012)$ discovered, in fMRI and MEG trials, that sentences with arm- and leg-related words used in idiomatic or literal sense (e.g. He kicked the habit vs. He kicked the statue) each activated corresponding areas of motor cortex in a rapid fashion (within 150/200 ms). Convergent results were found by Lauro et al. (2013) even though this time with less statistical significance. The interpretation of these last results is similar to the one given by Aziz-Zadeh and Damasio (2008): The more the meaning of a non-literal expression becomes conventional and abstract, the more the motor component in its semantics is lost. This would cause consequent weaker and rarer activation of perceptual and motor brain areas. 
To sum up, the neuroimaging evidence analyzed so far suggests that the sensorymotor circuits of the cortex play a role in processing and representing literal linguistic items associated with movement in a somatotopic way. In particular, this faculty is thought to be provided by MNs, given their capability of activating such a strong resonance mechanism (Glenberg and Gallese 2012; Kemmerer 2014). The same conclusion cannot be drawn with the same body of evidence concerning figurative movement as there are still methodological and theoretical issues to be further analyzed before reaching convincing conclusions.

In the next paragraph I deal with some of these issues and review the main critical arguments against embodied theories in meaning construction as well as those regarding the involvement of $\mathrm{MN}$.

\section{Comprehension or Imagery?}

A serious issue has been recently raised concerning the results of the experiments reviewed above. Some scholars (Mahon and Caramazza 2008; Lingnau et al. 2009) have advanced the hypothesis that the activation of the sensory-motor circuits is caused by a process of imagery of the motion sentence rather than being a direct comprehension process. According to this view, the verb-induced activation would be the result of a post-comprehension process that relies on some sort of internal thought or decoding process that acts before the premotor cortex. Mahon and Caramazza explain:

It would have to be known [...] what types of cognitive processes are interposed between the perception of the action word and the activation of the motor system. In other words, it would have to be known that the activation of the motor system was not mediated by the retrieval of 'abstract' conceptual content. (2008: 61)

The issue raised by Mahon and Caramazza is clear and brings us back to a secondary embodied theory of meaning construction: Between perception and comprehension there has to be a symbolic manipulation process of some sort. The question is still open. Did the participants in the previously reviewed experiments evoke motor images in their mind after perceiving the verb stimuli?

There are two main counter-answers to this issue. The first one relies on the activation speed of the motor system after input perception. It has been demonstrated that MNs in the motor cortex fire even after perceiving a $50 \mathrm{~ms}$ linguistic stimulus, a sort of subliminal presentation of linguistic items, and this would exclude every thought-process between stimuli and cortex activation (Boulenger et al. 2008, see also Glenberg and Gallese 2012). Other studies (see a discussion in Glenberg 2007; Kemmerer and Gonzales-Castillo 2010; Liuzza et al. 2010) suggest that motor resonance, especially in the premotor cortex, occurs very quickly during action verb comprehension. There would not be enough time to process the stimuli via imagery or thought. According to these claims, such a high activation speed demonstrates the 
fact that motor areas of our brain are directly involved in primary semantic processes of action verbs.

The second counter-answer to the issue raised by Mahon and Caramazza comes from medicine and has to do with Motor Neuron Disease (MND) patients. MND is a degenerative disease of the motor neurons that practitioners and researchers have classically approached as a solely neurological syndrome, being reluctant to consider its intrinsic dual nature. As Bak and Chandran (2012) report, only recently has the dual nature of MND been recognized; both cognitive, psychiatric, and neurological symptoms are observed in MND patients. In particular, the first steps of this disease are cognitive and usually related to language, such as non-fluent aphasia and semantic dementia; secondary symptoms can be behavioural or psychiatric and, only later, muscular problems, such as fasciculations or weakness, arise. A large body of research has demonstrated that MND patients are linguistically impaired in selecting and using appropriately linguistic items - specifically verbs-related to movement (Bak and Hodges 2004; Bak et al. 2006; Bak and Chandran 2012). Also other neurodegenerative diseases such as Parkinsons can affect linguistic abilities related to the semantics of motion verbs (Rodriguez-Ferreiro et al. 2009). The movement-related impairments, both at a linguistic and at a physical level, should be "viewed as different manifestations of the same underlying pathological process" (Bak and Chandran 2012: 942) and should be considered as compelling evidence of the role played by the body in movement-related semantics (but see Maieron et al. 2013 for a slightly different perspective about neurosurgical patients affected by cerebral tumor).

These observations about the activation speed of the sensory-motor areas and about the need of an intact motor system for action verb comprehension lead us to consider the role of MNs as a crucial one in the processing of literal motion verbs and sentences, and makes their fundamental role clearer in the Embodied Semantic paradigm.

\section{Some Proposals for Further Research}

I have discussed, so far, about motion verbs without further investigating any linguistic theory about them. Research on motion verbs is huge and has produced a large amount of theories and evidence about how movement is codified in language. It would be impossible, in this paper, to propose even a short summary of these studies. Nevertheless, it seems particularly relevant to inquire here how linguistic relativity plays an important role in cognition.

A very important distinction has been made by Talmy (2000) and Slobin (2003, 2004) between verb-framed and satellite-framed languages. According to these scholars the semantics of motion verbs can be divided into a path (the core feature of a motion event) and manner (the way this movement is carried out). According to Talmy and Slobin (see Ponterotto 2012 for a brief discussion), the world languages can be divided into verb-languages and satellite-languages. The first group classifies 
path in the verb and manner in a satellite (usually a preposition); in the second group, vice versa, path is classified in the satellite and manner in the verb.

Let us consider, for the sake of clarity, the following examples:

(1) The dog ran into the house

(2) Le chien est entré dans la maison en courant

(3) Il cane è entrato in casa correndo.

Example number 1 shows that English, as many other German languages, encodes the manner of motion in the verb and the path in a satellite, usually a preposition (into). French and Italian (examples 2 and 3), as do Romance languages, encode the path in the verb and the manner of motion in a satellite (en courant and correndo). ${ }^{5}$

Slobin demonstrated in various studies $(2003,2004,2008)$ that speakers of different languages classify and codify movement in different ways: the macroscopic distinction between verb- and satellite-languages plays a role in cognition and on the way we conceptualize movement, in particular in narrative tasks:

Habitual means for describing physical paths appear to influence mental processes involved in the conceptualization of motion events. Language-specific differences show up in strategies for the presentation of both Path and Manner information in narratives - oral as well as written, produced by children as well as adults. (2008: 200)

Other interesting experiments aimed at studying how linguistic relativity is involved in movement cognition are the ones conducted by Cardini $(2009,2012)$ with Italian and English speakers. In his first study, Cardini (2009) showed how Italian speakers, when reporting motion events, made use of a statistically significant larger amount of path verbs than their English counterparts that recurred almost systematically to manner verbs in their descriptions. In his second study, Cardini (2012) demonstrated via a grammatical judgement task assigned to Italian mother tongue informants that there are some grammatical constraints related to Italian motion verbs and path prepositions that play a major influence on the use of manner of motion verbs in the conceptualization of motion events.

Furthermore, Kita and Özyürek (2003) and Özyürek and Kita (1999) tested the language relativity hypothesis on gesture. In elicited narrative tasks of speakers of satellite- and verb-languages, important differences were found regarding the gestures used during the oral narrative tasks. According to these experiments, it would seem that linguistic relativity strongly influences gesture.

Linguistic relativity, widely displayed by languages when codifying movement, plays a significant role in movement cognition. I pose the question, here, as to whether it would be worthwhile to give more consideration to linguistic relativity in future experiments on motion verbs within the framework of Embodied Semantics.

\footnotetext{
${ }^{5}$ Even if in Italian a sentence like "il cane corse in casa" (literally translated as "the dog run into the house") is grammatical. This shows that Italian, to a higher extent than other Romance languages, can reduplicate the Germanic conflation according to the semantics of the verb: if it contains traits of force, speed or intensity, motion and manner can conflate as usually happens in Germanic languages (see Baicchi 2010).
} 
All the experiments that I reviewed in Sects. 3 and 4 have been carried out only in four languages, Italian (the most tested language), English, Spanish and Dutch. It would be certainly interesting to describe more accurately the movement-related linguistic input and accordingly analyze whether linguistic relativity in movement triggers different activation in the premotor cortex via the MNs system.

Psycholinguistics studies have demonstrated that path and manner of motion are codified in different regions of the brain. Wu et al. (2008) demonstrated in a triple experimental fMRI study that there is a neural decomposition of semantic information regarding motion events and that this neural decomposition process follows the linguistic parsing of motion into different constituents (manner and path). Wu and colleagues discovered that the processing of English verbs encoding manner activates the left posterior parietal gyrus, while English prepositions encoding path activate mainly the posterior inferior parietal lobule, as reported also in Emmorey et al. (2002). Similar conclusions have been reached by analyzing the location of cortical lesions in English-speaking patients with comprehension deficits in the manner of motion (i.e. verbs, in English) and in locative relations such as path (i.e., prepositions, in English). Different kinds of motion description impairments are caused by different localizations of the lesions, conforming to what $\mathrm{Wu}$ et al. reported in their 2008 study (Tranel and Kemmerer 2004; Wu et al. 2007).

Given this behavioral and neuropsychological evidence about the strong role played by language relativity in movement semantics, I pose here the question of whether it would be interesting to further explore the different typology of languages used in the experimental stimuli. Would the sensory-motor areas activated by a movement sentence trigger according to the linguistic parsing of motion of that particular language? According to the Linguistic Focus Hypothesis (Taylor and Zwaan 2008), the motor-resonance activation occurs mainly at the verb position and dissipates within the next few words in the sentence. It would be interesting to test if the motor resonances activated by the verb of a sentence somehow conform to the kind of movement information encoded in the verb: Would a path-encoding verb such as one in a Romance language activate mainly posterior inferior parietal lobule areas as demonstrated by Wu et al. (2008)? In other words, would our brain simulate the semantic content of a path-encoding verb similarly to a preposition, i.e., similarly to a linguistic object expressing spatial relations and not movement qualities? And, furthermore, would this sensory-motor activation be congruent both in comprehension and production tasks of the same kind of movement verbs? Positive evidence of this hypothesis would further confirm that language relativity plays a congruent role not only in cognitive behaviors, but also in the anatomical architecture of meaning in the human cortex. ${ }^{6}$

\footnotetext{
${ }^{6}$ In a recent paper, Kemmerer (2017) has maintained that the research devoted to understanding how categories of object concepts are represented in the human brain is severely limited as it has been carried out mainly with European languages. Linguistic relativity influences the neural underpinnings of object concepts classification, as the author demonstrates by reviewing a number of studies that look at the different outcomes of psychological and neurobiological experiments conducted with speakers of languages with (e.g. Chinese and Burmese) and without (e.g. English and Russian) a nominal classification system for objects properties such as shape and size. Kemmerer's
} 
Furthermore, second language acquisition studies have demonstrated that L2 learners find a great amount of difficulty in changing their way of describing motion events when the target language is typologically different from their mother tongue in respect to the encoding of manner and path information. Cadierno (2004) and $\mathrm{Wu}$ (2011) describe the process of attuning to the features of the target language as a difficult and time-consuming endeavor that usually encompasses mixed stages where both the property of the mother tongue and of the target language are displayed. It would be interesting to compare, although still on a very speculative basis, how differently would the sensory-motor system of a second language learner react to the same linguistic stimuli expressed both in his mother tongue and in the second language being learned. Could we hypothesize that, at least for the first stages of learning, the neural activation overlaps due to the high transfer phenomena detected in learners engaged in acquiring a different way of expressing motion events? Or, even from the first acquisition stages, could different neural activation be recorded, according to the different typology of the two languages involved? In a recent study, Foroni (2015) recorded congruent facial muscle activation in response to facial-motion-related linguistic items (such as to smile and similar verbs) also in L2 speakers of English, although with some variations in comparison with L1 speakers. Foroni maintains that motor resonance mechanisms are to be found also in L2 speakers, although these results must be further validated before they can be generalized. Furthermore, Foroni's study is a first, interesting attempt to ascertain the role of mirror areas in L2 meaning construction that, however, does not address any issue related to linguistic relativity in L1/L2 motion verbs.

\section{Conclusion}

This chapter associated a relatively new paradigm in linguistics, Embodied Semantics, to Mirror Neuron activation caused by the perception of linguistic items related to movement. My aim was to review some recent literature, investigating the provocative notion that perceiving movement in language means triggering those cerebral areas deputed to body movement.

In Sect. 1, I tried to give an up-to-date overview of the theories of embodiment, starting from the amodal stance and concluding with the strong embodied theory of meaning construction.

A complete definition of what constitutes embodiment requires a proper statement of what we consider "body". In Sect. 2, I maintained that a phenomenological approach to the concept of body appears to be a suitable one for our purposes: referring to Merleau-Ponty's work, concepts are embodied in a living organism that is

claims, even if not directly addressed to movement semantics, can be taken as an indirect support to the proposal that linguistic relativity should be taken in serious consideration also when dealing with brain representations of movement expressions. 
constituted by a brain-body unity, a concrete living entity and its neural representation that helps us give meaning to the world around us.

In Sect. 3, I introduced the properties of MNs and briefly summarized the experimental evidence of their existence in the human brain. Section 4 explored the relationship between MNs and Embodied Semantics. Experimental evidence has so far highlighted a role of the activation of the premotor cortex in movement meaning construction. MNs are thought to be the neurophysiological substrate that enacts this activation, even if some issues recently raised have criticized these findings. In particular, the activation speed of the premotor cortex has to be considered more clearly, since it plays a crucial role in discriminating the origin of this resonance mechanism: Is it imagery or thought-related or is it a direct and non-propositional semantic understanding process? Section 5 was dedicated to this debate, reviewing neuroscientific and medical literature.

In Sect. 6, I have proposed that future research in Embodied Semantics should take into consideration movement-related linguistic relativity as it has been widely demonstrated that it influences cognition and the neurophysiology of motion events. I also suggested considering how linguistic relativity and language competence can be interrelated, proposing to study also second language learners as possible informants of how sensory-motor resonance mechanism can modulate differently according to both linguistic proficiency and L1 and L2 differences in encoding movement events.

In conclusion, the role played by MNs in Embodied Semantics seems to be experimentally demonstrated, at least when taking into consideration the processing of literal movement sentences. Further evidence is needed to finally demonstrate their involvement in abstract motion events. Future research should more fully consider language relativity in movement semantics, the role of the context and the cotext in which the linguistic items used in the experiments are situated, and L2 speakers. These are three issues that have been somewhat underestimated in experimental literature on the relationship between MNs and Embodied Semantics.

\section{References}

Atkinson, D. (2012). Cognitivism, adaptive intelligence and second language acquisition. Applied Linguistics Review, 3(2), 211-232.

Adenzato, M., \& Garbarini, F. (2006). The as if in cognitive science, neuroscience and anthropology. Theory and Psychology, 16, 749-759.

Aziz-Zadeh, L., \& Damasio, A. (2008). Embodied semantics for actions: Findings from functional brain imaging. Journal of Physiology, 102, 35-39.

Aziz-Zadeh, L., Wilson, S., Rizzolatti, G., et al. (2006). Congruent embodied representations for visually presented actions and linguistic phrases describing actions. Current Biology, 16, $1813-1823$.

Baicchi, A. (2010). Some observations on the typological constraints on translation: The case of directed motion constructions. In G. Palumbo (Ed.), I vincoli del tradurre (pp. 109-122). Roma: Officina Edizioni.

Bak, T., \& Chandran, S. (2012). What wires together dies together: Verbs, actions and neurodegeneration in motor neuron disease. Cortex, 48, 936-944. 
Bak, T., \& Hodges, J. R. (2004). The effects of motor neurone disease on language: Further evidence. Brain and Language, 89, 354-361.

Bak, T., Yancopoulou, D., Nestor, P. J., et al. (2006). Clinical, imaging and pathological correlates of a hereditary deficit in verb and action processing. Brain, 129(2), 321-332.

Barsalou, W. (1999). Perceptual symbol system. Behavioural and Brain Science, 22, 577-660.

Boulenger, V., Mechtouff, L., Thobois, S., et al. (2008). Word processing in Parkinson's disease is impaired for action verbs but not for concrete nouns. Neuropsychologia, 46(2), 743-756.

Boulenger, V., Hauk, O., \& Pulvermüller, F. (2009). Grasping ideas with the motor system: Semantic somatotopy in idiom comprehension. Cerebral Cortex, 19, 1905-1914.

Boulenger, V., Shtyrov, Y., \& Pulvermüller, F. (2012). When do you grasp the idea? MEG evidence for instantaneous idiom understanding. Neuroimage, 59(4), 3502-3513.

Buccino G., Lui F., Canessa N., et al. (2004). Neural circuits involved in the recognition of actions performed by nonconspecifics: An FMRI study. Journal of Cognitive Neuroscience, 16(1), 114-126.

Buccino, G., Riggio, L., Melli, G., et al. (2005). Listening to action-related sentences modulates the activity of the motor system: A combined TMS and behavioural study. Cognitive Brain Research, $24,355-363$.

Cacciari, C., \& Pesciarelli, F. (2013). Motor activation in literal and non-literal sentences: Does time matters? Frontiers in Human Neuroscience, 7, 202.

Cacciari, C., Pellicciari, M. C., Fogliata, A., et al. (2010). The motion component as preserved in metaphorical sentences. A TMS study. In P. M. Bertinetto et al. (Eds.) Proceedings of verb 2010. The identification and representation of verb features (pp. 20-23). Pisa: Scuola Normale Superiore.

Cacciari, C., Pellicciari, M. C., Bolognini, N., et al. (2011). Literal, fictive and metaphorical motion sentences preserve the motion component of the verb. A TMS study. Brain and Language, 119, $149-157$.

Cadierno, T. (2004). Expressing motion events in a second language: A cognitive typological perspective. In M. Achard \& S. Niemeier (Eds.), Cognitive linguistics, second language acquisition, and foreign language teaching (pp. 13-49). Berlin: Mouton de Gruyter.

Caramazza, A., \& Mahon, B. Z. (2003). The organization of conceptual knowledge: The evidence from category-specific semantic deficits. Trends in Cognitive Sciences, 7(8), 354-361.

Caramazza, A., Anzellotti, S., Strnad, L., et al. (2014). Embodied cognition and mirror neurons: A critical assessment. Annual Review of Neuroscience, 37, 1-15.

Cardini, F. E. (2009). Testing linguistic relativity: A comparison between English and Italian in the domain of manner of motion. Saarbrücken: VDM Verlag Dr. Müller.

Cardini, F. E. (2012). Grammatical constraint and verb-framed languages: The case of Italian. Language and Cognition, 4(3), 167-201.

Chomsky, N. (1966). Cartesian linguistics. A chapter in the history of rational thought. New York: Harper and Row.

Cook, R., Bird, G., Catmur, C., et al. (2014). Mirror neurons: From origins to function. Behavioural and Brain Sciences, 37, 177-241.

Cuccio, V., Ambrosecchia, M., Ferri, F., et al. (2014). How the context matters. Literal and figurative meaning in the embodied language paradigm. PLOS ONE, 9(12), 1-24.

Descartes, R. (1637). Discours de la méthode (English edition, R. Descartes (1970) The philosophical works, Trans.). New York: Cambridge University Press.

de Vega, M., León, I., Hernández, J. A., et al. (2014). Action sentence activate sensory motor regions in the brain independently of their status of reality. Journal of Cognitive Neuroscience, 26(7), $1363-1376$.

Dirven, R. (2005). Major strands in cognitive linguistics. In A. Baicchi, C. Broccias, \& A. Sansò (Eds.), Modelling thought and constructing meaning (pp. 11-40). Milan: Franco Angeli.

Dirven, R., \& Ruiz de Mendoza, F. (2010). Looking back at 30 years of Cognitive Linguistics. In E. Tabakowska, M. Choinisky, \& L. Wiraszka, (Eds.) Cognitive linguistics in action. From theory to application and back (pp. 11-70). Berlin: Mouton De Gruyter. 
Dove, G. (2015). How to go beyond the body: An introduction. Frontiers in Psychology, 6, 660-663.

Dove, G. (2016). Three symbol ungrounding problems: Abstract concepts and the future of embodied cognition. Psychonomic Bulletin \& Review, 23, 1109-1121.

Emmorey, K., Damasio, H., McCullough, F., et al. (2002). Neural systems underlying spatial language in American sign language. NeuroImage, 17, 812-824.

Fadiga, L., \& Craighero, L. (2004). Electrophysiology of action representation. Journal of Clinical Neurophysiology, 21, 157-169.

Fadiga, L., Craighero, L., \& Olivier, E. (2005). Human motor cortex excitability during the perception of others' action. Current Opinion in Neurobiology, 15, 213-218.

Fernandino, L., \& Iacoboni, M. (2010). Are cortical motor maps based on body parts or coordinated actions? Implications for embodied semantics. Brain and Language, 112, 44-53.

Ferrari, P. F., Gallese, V., Rizzolatti, G., et al. (2003). Mirror neurons responding to the observation of ingestive and communicative mouth actions in the monkey ventral premotor cortex. European Journal of Neuroscience, 17, 1702-1714.

Fodor, J. A. (1975). The Language of thought. Cambridge MA: Harvard University Press.

Fogassi, L., Coudè, G., \& Ferrari, P. F. (2013). The extended features of mirror neurons and the voluntary control of vocalization in the pathway to language. Language and Cognition, 5, 145-155.

Foroni, F. (2015). Do we embody second language? Evidence for 'partial' simulation during processing of a second language. Brain and Cognition, 99, 8-16.

Foroni, F., \& Semin, G. R. (2009). Language that puts you in touch with your bodily feelings. The multimodal responsiveness of affective expressions. Psychological Science, 20(8), 974-980.

Gallese, V. (2005). Embodied simulation: From neurons to phenomenal experience. Phenomenology and Cognitive Science, 4, 23-48.

Gallese, V. (2008). Empathy, embodied simulation and the brain: Commentary on Aragno and Zepf/Hartmann. Journal of the American Psychoanalytic Association, 56, 769-781.

Gallese, V., \& Lakoff, G. (2005). The brain's concepts: The role of the sensory-motor system in conceptual knowledge. Cognitive Neuropsychology, 22, 455-479.

Gallese, V., Fadiga, L., Fogassi, L., et al. (1996). Action recognition in the premotor cortex. Brain, 119, 593-609.

Glenberg, A. (2007). Language and action: Creating sensible combinations of ideas. In G. Gaskell (Ed.), The Oxford handbook of psycholinguistics (pp. 361-371). Oxford: Oxford University Press.

Glenberg, A., \& Gallese, V. (2012). Action-based language: A theory of language acquisition, comprehension, and production. Cortex, 48(7), 905-922.

Glenberg, A., Sato, M., Cattaneo, L., et al. (2008). Processing abstract language modulates motor system activity. The Quarterly Journal of Experimental Psychology, 6, 905-919.

Hauk, O., Johnsrude, I., \& Pulvermüller, F. (2004). Somatotopic representation of action words in human motor and premotor cortex. Neuron, 41, 301-307.

Hickok, G. (2014). The myth of mirror neurons: The real neuroscience of communication and cognition. New York: W. W. Norton.

Johnson, M., \& Lakoff, G. (2002). Why cognitive linguistics requires embodied realism. Cognitive Linguistics, 13(3), 245-263.

Kemmerer, D. (2014). Visual and motor features of action verbs: A cognitive neuroscience perspective. In R. G. de Almeida \& C. Manouilidou (Eds.), Cognitive science perspectives on verb representation and processing (pp. 189-209). New York: Springer.

Kemmerer, D. (2015). Does the motor system contribute to the perception and understanding of actions? Reflections on Gregory Hickok's The myth of mirror neurons: The real neuroscience of communication and cognition. Language and Cognition, 7(3), 450-475.

Kemmerer, D. (2017). Categories of object concepts across languages and brains: the relevance of nominal classification systems to cognitive neuroscience. Language, Cognition and Neuroscience, $32,401-424$.

Kemmerer, D., \& Gonzales-Castillio, J. (2010). The two-level of verb meaning: An approach to integrating the semantics of action with the mirror neuron system. Brain and Language, 112, $54-76$. 
Kemmerer, D., Gonzales-Castillio, J., Talavage, T., et al. (2008). Neuroanatomical distribution of five semantic components of verbs: Evidence from fMRI. Brain and Language, 107, 16-43.

Kilner, J. M., \& Lemon, R. M. (2013). What we know currently about mirror neurons. Current Biology, 23, 1057-1062.

Kita, S., \& Özyürek, A. (2003). What does cross linguistic variation in semantic coordination of speech and gesture reveal?: Evidence for an interface representation of spatial thinking and speaking. Journal of Memory and Language, 48(1), 16-32.

Kraskov, A., Dancause, N., Quallo, M. M., et al. (2009). Corticospinal neurons in macaque ventral P.C. with mirror properties: A potential mechanism for action suppression? Neuron, 64, 922-930.

Lafuente, V., \& Romo, R. (2004). Language abilities of motor cortex. Neuron, 41, 178-180.

Lambon Ralph, M. A. (2014). Neurocognitive insights on conceptual knowledge and its breakdown. Proceedings of the Royal Society, Biological Sciences, 369, 1634.

Lakoff, G., \& Johnson, M. (1999). Philosophy in the flesh: The embodied mind and its challenge to Western thought. New York: Basic Books.

Lauro, L., Mattavelli, G., Papagno, C., et al. (2013). She runs, the road runs, my mind runs, bad blood runs between us: Literal and figurative motion verbs: An fMRI study. Neuroimage, 83, 361-271.

Lingnau, A., Gesierich, B., \& Caramazza, A. (2009). Asymmetric fMRI adaptation reveals no evidence for mirror neurons in humans. Proceedings of the National Academy of Sciences, 106, 9925-9930.

Liuzza, M. T., Cimatti, F., \& Borghi, A. (2010). Lingue, corpo, pensiero: le ricerche contemporanee. Roma: Carocci.

Mahon, B. Z. (2015). The burden of embodied cognition. Canadian Journal of Experimental Psychology, 69, 172-178.

Mahon, B. Z., \& Caramazza, A. (2008). A critical look at the embodied cognition hypothesis and a new proposal for grounding conceptual content. Journal of Physiology, 102, 59-70.

Maieron, M., Marin, D., Fabbro, F., et al. (2013). Seeking a bridge between language and motor cortices: A PPI study. Frontiers in Human Neuroscience, 7, 249.

Merleau-Ponty, M. (1962). Phenomenology of perception. London: Routledge and Kegan Paul.

Meteyard, L., Rodriguez, Cuadrado, S., Bahrami, B., et al. (2012). Coming of age: A review of embodiment and the neuroscience of semantics. Cortex, 48, 788-804.

Mukamel, R., Ekstrom, A. D., Kaplan, J., et al. (2010). Single neuron responses in humans during execution and observation of actions. Current Biology, 20, 750-756.

Özyürek, A., \& Kita, S. (1999). Expressing manner and path in English and Turkish: Differences in speech, gesture and conceptualization. In M. Hahn, \& C. Stoness (Eds.) Proceedings of the twenty first annual conference of the cognitive science society (pp. 507-512). London: Erlbaum.

Ponterotto, D. (2012). Metaphorical aspects of motion verbs: A contrastive view of English and Italian. In G. Mininni, \& A. Manuti (Eds.) Applied psycholinguistics. Positive and ethical perspectives (Vol. 1, pp. 407-418). Milan: FrancoAngeli.

Pulvermüller, F. (2005). Brain mechanisms linking language and action. Nature Reviews Neuroscience, 6, 576-582.

Pulvermüller, F. (2008). Grounding language in the brain. In M. de Vega, A. Graesser, \& A. Glenberg (Eds.), Symbols and embodiment: Debates on meaning and cognition (pp. 85-116). Oxford: Oxford University Press.

Rakova, M. (2002). The philosophy of embodied realism: A high price to pay? Cognitive Linguistics, 13(3), 215-244.

Raos, V., Evangeliou, M. N., \& Savaki, H. E. (2007). Mental simulation of action in the service of action perception. Journal of Neuroscience, 27, 12675-12683.

Rizzolatti, G., \& Craighero, L. (2004). The mirror-neuron system. Annual Review of Neuroscience, 27, 169-192.

Rizzolatti, G., Fadiga, L., Gallese, V., et al. (1996). The premotor cortex and the recognition of motor actions. Cognitive Brain Research, 3, 131-141. 
Rizzolatti, G., Fogassi, L., \& Gallese, V. (2001). Neurophysiological mechanism underlying the understanding and imitation of action. Nature Reviews Neuroscience, 2, 661-670.

Rizzolatti, G., \& Sinigaglia, C. (2008). Mirrors in the brain. Oxford: Oxford University Press.

Rodriguez-Ferreiro, J., Menendez, M., Ribacoba, R., et al. (2009). Action naming is impaired in Parkinson disease patients. Neuropsychologia, 47(14), 3271-3274.

Sambre, P. (2012). Fleshing out language and intersubjectivity: An exploration of Merleau-Ponty's legacy to cognitive linguistics. Journal of Cognitive Semiotics, 4(1), 189-224.

Slobin, D. (2003). Language and thought online: Cognitive consequences of linguistic relativity. In D. Gentner \& S. Goldin-Meadow (Eds.), Language in mind: Advances in the study of language and thought (pp. 157-192). Cambridge MA: MIT Press.

Slobin, D. (2004). The many ways to search for a frog: Linguistic typology and the expression of motor event. In S. Strömqvist \& L. Verhoeven (Eds.), Relating events in narrative (Vol. 2, pp. 219-257)., Typological and contextual perspectives Mahwah: Lawrence Erlbaum Associates.

Slobin, D. (2008). Relations between paths of motion and paths of vision: A crosslinguistic and developmental exploration In V. M. Gathercole (Ed.), Routes to language: Studies in honor of Melissa Bowerman (pp. 197-221). Mahwah: Lawrence Erlbaum Associates.

Talmy, L. (2000). Toward a cognitive semantics. Cambridge, Massachusetts: MIT Press.

Taylor, L., \& Zwaan, R. (2008). Motor resonance and linguistic focus. Quarterly Journal of Experimental Psychology, 61, 896-904.

Tettamanti, M., Buccino, G., Saccuman, M. C., et al. (2005). Listening to action-related sentences activates fronto-parietal motor circuits. Journal of Cognitive Neuroscience, 17, 273-281.

Tranel, D., \& Kemmerer, D. (2004). Neuroanatomical correlates of locative prepositions. Cognitive Neuropsychology, 21, 719-749.

Violi, P. (2003). Embodiment at the crossroads between cognition and semiosis. Recherches en Communication, 19, 199-234.

Violi, P. (2008). Beyond the body: Towards a full embodied semiosis. In M. Frank, R. Dirven, T. Ziemke, et al. (Eds.), Body, language and mind. Vol 2: Sociocultural Situatedness (pp. 53-76). Berlin: Mouton De Gruyter.

Wu, D., Morganti, A., \& Chatterjee, A. (2008). Neural substrates of processing path and manner information of a moving event. Neuropsychologia, 46(2), 704-713.

Wu, D., Waller, S., \& Chatterjee, A. (2007). The functional neuroanatomy of thematic role and locative relational knowledge. The Journal of Cognitive Neuroscience, 19, 1542-1555.

Wu, S. L. (2011). Learning to express motion events in an L2: The case of Chinese directional complements. Language Learning, 61, 414-454.

Zlatev, J. (2007). Embodiment, language and mimesis. In T. Ziemke, J. Zlatev, J., \& F. Roslyn (Eds.) Body, language, mind. Vol 1: Embodiment (pp. 241-281). Berlin: Mouton de Gruyter.

Zwaan, R. (2014). Embodiment and language comprehension: Reframing the discussion. Trends in Cognitive Sciences, 18, 229-234. 